\title{
Negative Regulation of Histamine Release
}

National Cancer Institute

\section{Source}

National Cancer Institute. Negative Regulation of Histamine Release. NCI Thesaurus.

Code C41528.

Any process that reduces the release of the biogenic amine and neurotransmitter histamine. Histamine activity is reduced by inhibition of histamine synthesis or destruction of histamine-releasing neurons in the brain. This process is involved in suppression of allergies and induction of sleep. 